\title{
SCIENTIFIC ORGANIZING COMMITTEE
}

B. V. Kukarkin (Chairman), P. F. Chugainov, L. Detre, M. W. Feast, S. C. B. Gascoigne, R. E. Gershberg, G. Haro, G. H. Herbig, L. V. Mirzoyan, L. Plaut (Editor of the Proceedings), and L. Rosino.

\section{LOCAL ORGANIZING COMMITTEE}

V. A. Ambartsumian (Chairman), A. G. Massevitch (Vice-Chairman), G. S. Khromov (Executive Secretary), A. A. Boyarchuk, B. V. Kukarkin, D. Y. Martinov, V. A. Minin, E. C. Kharadze, S. G. Korneev, and G. G. Chahmahchev. 